\title{
Measurement of the Neutral B Meson-B Bar Meson Oscillation Frequency Using Dilepton Events at BABAR
}

\author{
Ming Chao \\ Stanford Linear Accelerator Center \\ Stanford University \\ Stanford, CA 94309
}

SLAC-Report-829

Prepared for the Department of Energy
der contract number DE-AC02-76SF00515

Printed in the United States of America. Available from the National Technical Information Service, U.S. Department of Commerce, 5285 Port Royal Road, Springfield, VA 22161. 
This document, and the material and data contained therein, was developed under sponsorship of the United States Government. Neither the United States nor the Department of Energy, nor the Leland Stanford Junior University, nor their employees, nor their respective contractors, subcontractors, or their employees, makes an warranty, express or implied, or assumes any liability of responsibility for accuracy, completeness or usefulness of any information, apparatus, product or process disclosed, or represents that its use will not infringe privately owned rights. Mention of any product, its manufacturer, or suppliers shall not, nor is it intended to, imply approval, disapproval, or fitness of any particular use. A royalty-free, nonexclusive right to use and disseminate same of whatsoever, is expressly reserved to the United States and the University. 


\title{
MEASUREMENT OF THE $B^{0} \bar{B}^{0}$ OSCILLATION FREQUENCY USING DILEPTON EVENTS AT BABAR
}

\author{
DISSERTATION \\ submitted in partial satisfaction of the requirements \\ for the degree of
}

\section{DOCTOR OF PHILOSOPHY}

in Physics

by

Ming Chao

Dissertation Committee:

Professor Andrew Lankford, Chair Professor Myron Bander

Professor David Kirkby 


\section{Table of Contents}

Litst of figures

List of Tables $\quad$ xit

ACKNOWLEDGMENTS xwii

CURRICULUM VTTAE xvili

ABSTRACT OF THE DISSEKTATION xix

1 Introduction

2 Theory and Formulas 5

2.1 Review of $B^{a}-\bar{B}^{0}$ Mixing $\ldots \ldots \ldots \ldots \ldots$

$22 B^{0}-B^{n}$ Mixing in the Standard Model $\ldots \ldots \ldots \ldots \ldots$

$2.21 B$ Meson Decay Constant $f_{a} \ldots \ldots \ldots \ldots$

2.2 .2 Bag Parameter $b_{2} \ldots \ldots \ldots \ldots \ldots \ldots$

$23 B^{3}-B^{0}$ Wixing Beyond the Standard Model $\ldots \ldots \ldots \ldots$ is

2.3 .1 Left-Right Symmetry . . . . . . . . . . . 15

23.2 Supersymmetry, ................ 17

233 Little Higgs Model $\ldots \ldots \ldots \ldots \ldots \ldots \ldots \ldots \ldots$

2.4 Time Exolution Formalism . . . . . . . . . . . . . . . 19 
3 The BABAR Experiment

3.1 PEP-II Facility $\ldots \ldots \ldots \ldots \ldots \ldots$

3.2 Overtiew of the BABAR Detector . . . . . . . . . . . . . . 29

3.3 Silicon Vertex Tracker . . . . . . . . . . . . . . . . 31

3.4 Drift Chamber $\ldots \ldots \ldots \ldots \ldots \ldots \ldots \ldots \ldots$

3.5 Detector of Intemally Reflected Cererkov light $\ldots \ldots \ldots \ldots$. . . 38

3.6 Electronagnetic Calorimeter . . . . . . . . . . . 40

3.7 Instrumented thux Retum $\ldots \ldots \ldots \ldots \ldots \ldots \ldots$

3.8 Trigger System $\ldots \ldots \ldots \ldots \ldots \ldots \ldots \ldots$

3.9 Data Acquisition and Online Computing $\ldots \ldots \ldots \ldots$

4 Event Selection and Classification 49

41 Data Sets $\ldots \ldots \ldots \ldots \ldots \ldots \ldots \ldots \ldots \ldots$

4.2 Selection of Direct Dilepton Pairs $\ldots \ldots \ldots \ldots \ldots \ldots \ldots$

4.3 Lepton Identrftcation $\ldots \ldots \ldots \ldots \ldots \ldots \ldots \ldots$

4.3 .1 Electron Identification $\ldots \ldots \ldots \ldots \ldots \ldots \ldots \ldots$

4.3 .2 Mwon Idertification $\ldots \ldots \ldots \ldots \ldots \ldots$

4.4 Skim Cuts and Ntuple Production $\ldots \ldots \ldots \ldots \ldots$

45 Propertime difference $4 \ldots \ldots \ldots \ldots \ldots$

4.5 .1 Estriation of the Dexay Vertices . . . . . . . . . 57

4.52 Calculation of $\Delta t \ldots \ldots \ldots \ldots \ldots$

4.53 Calculation of error on $\Delta t \ldots \ldots \ldots \ldots \ldots$

4.6 Baskground Reduction . . . . . . . . . . . . . . 61

$4.6,1$ Reduction of Tails of $\Delta z$ Resolution $\ldots \ldots \ldots \ldots \ldots$

46.2 Continuum Background . . . . . . . . . . . 63

4.6 .3 Cascade Leptons . . . . . . . . . . . . . 64

4.6.4 Reduce the At dependence of signal resolution function . . 66

4.7 Remaining Backgrounds and Event Classification $\ldots \ldots \ldots \ldots$ 
5 Probability Density Function for Time Dependence

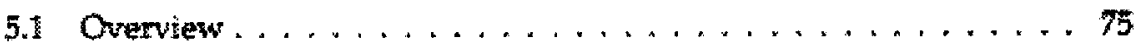

5.2 Determination of Fractions $\ldots \ldots \ldots \ldots \ldots \ldots \ldots$

5.3 Signal Model . . . . . . . . . . . . . . . 7

5.4 Opposite 8 Cascade Model (OBC) $\ldots \ldots \ldots \ldots \ldots$

5.5 Same $B$ Cascade Model $(S B C) \ldots \ldots \ldots \ldots \ldots$

$5.611 \mathrm{t}$. Model . . . . . . . . . . . . . . . . 97

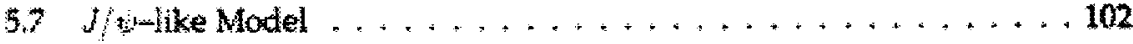

58 xtro Model $\ldots \ldots \ldots \ldots \ldots \ldots \ldots \ldots \ldots . \ldots \ldots$

59 Continuum Model $\ldots \ldots \ldots \ldots \ldots \ldots \ldots \ldots \ldots$

6 Data Analysis 113

61 Fit \$trategy $\ldots \ldots \ldots \ldots \ldots \ldots \ldots \ldots \ldots \ldots \ldots \ldots$

$6.2 B \bar{B}$ Monte Carlo Fit $\ldots \ldots \ldots \ldots \ldots \ldots \ldots \ldots \ldots$

6.3 On-resonance and Off-resonance Data Fit $\ldots \ldots \ldots \ldots \ldots \ldots$

64 Cross Check and Fit Validation $\ldots \ldots \ldots \ldots \ldots \ldots$

6. Ad.1 Toy Monte Carlo Shudy with $\Delta t$-dependent Resolutions ... 130

$6.4 \Delta \pi_{10}$ Bias Stidy with Different Angle Cats $\ldots \ldots \ldots \ldots 131$

6.4 Toy Monte Carlo Study and Goodness of Fit $\ldots \ldots \ldots 136$

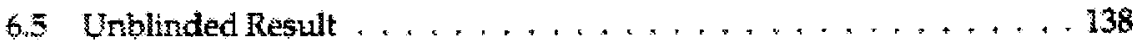

7 Systematics Uncettainties 139

71 blifetime ................... 140

7.2 Beam Enetgy $\ldots \ldots \ldots \ldots \ldots \ldots \ldots \ldots \ldots \ldots \ldots \ldots$

73 z Scale and SVT Alignrment $\ldots \ldots \ldots \ldots \ldots \ldots$

7.4 Beam Spot Postion . . . . . . . . . . . . . . 141

7.5 Particle Identification . . . . . . . . . . . . . 141

7.6 Signal Resolution $\ldots \ldots \ldots \ldots \ldots \ldots \ldots \ldots \ldots$ 
7.7 Continuum Parameterization $\ldots \ldots \ldots \ldots \ldots \ldots \ldots \ldots$

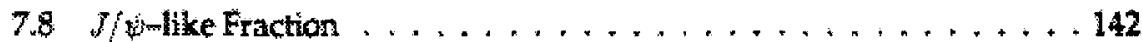

7.9 OBC Parameterization and Cascade Decays $\ldots \ldots \ldots \ldots \ldots \ldots$

7.10 SBC Parameterization $\ldots \ldots \ldots \ldots \ldots \ldots \ldots$

$7,11 \mathrm{dt}$ Parameterization $\ldots \ldots \ldots \ldots \ldots \ldots \ldots$

7.12 Xtra Parameterization $\ldots \ldots \ldots \ldots \ldots \ldots \ldots \ldots$

$\overline{7} .13$ Bias on $\Delta m_{1}$ from $B \bar{B}$ Monte Catlo . . . . . . . . . 145 


\section{List of Figures}

2. Examples of box diagratws for $B^{A}-B^{0}$ mixing in $S M$, left-right symmetric model, SUSY model and Little Higgs model . . . . . . . 10

2.2 Lowest order box diagrams for $B^{b}-B^{6}$ mixing with both $W$ gauge bosons and unphysical charged scalars $\phi^{ \pm}$in the loop. . . . . . . 11

2.3 Distributions of unmixed and mixed decay probabilities and asymmetry . . . . . . . . . . . . . . . . . . 24

3.1 A schernatic of the linear accelerator and the PEP-II storage rings. . . 27

3.2 An overview of the interaction region of the PEP-II machine. . . . 2 28

3.3 BARAR delector longitudinal section. . . . . . . . . . . 30

3.4 The Silicon Vertex Tracker sideview $\ldots \ldots \ldots \ldots \ldots \ldots \ldots$

3.5 The Silicon Vertex Tracker endview. . . . . . . . . . 32

3.6 SVT spatial resolution in $z$ and coordinate $\mathrm{k}$ microns as a function of track incident angle in degrees. . . . . . . . . . . 34

3.7 Longitudinal section of the BCH with principal dimensions .... 35

38 The track reconstruction efficiency in the $\mathrm{DCH} \ldots \ldots \ldots$

39 A schematic of the DIRC. . . . . . . . . . . 39

3,10 A longitudinat cross section of the EMC. . . . . . . . . 40

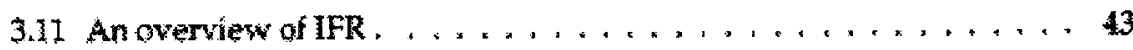

3.12 A schematic of the data acquisition system $\ldots \ldots \ldots \ldots$

3.13 A schematic of the hardware infrastructure of the online system. . . 48 
4.1 Sernileptonic decay of the b quark and charm quark ....... 51

4.2 Skematic of the difference between two $B$ decay vertices $\Delta z$ in the $r(4 S)$ decay. . . . . . . . . . . . . . . $\$ 7$

4.3 The estimation of the $B$ decay vertices using the POCA approach . . 58

4.4 RMS of the $A z$ error coming from the method of vertex fit versts the

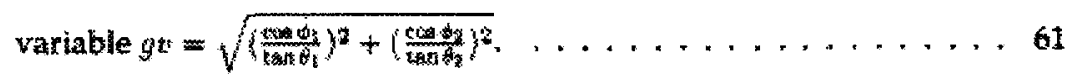

4.5 Distributions of the variables used in the Neural Network . . . 65

4.6 NNoutputs bor the two leptons for data and Monte Carlo. . . . . 66

4.7 RMS of $z$ residual as a function of $B$ decay distance for each lepton , 67

4.8 slopes of fit to the RMS of $z$ residual as a function of lepton angle cut 68

5.1 $\Delta t$ distributions for signal events in $B^{0} E^{0} \ldots \ldots \ldots \ldots \ldots$

$5.2 \Delta t$ distributons for stgnal events in $B^{+} B^{-} \ldots \ldots \ldots, \ldots \ldots, 80$

$\$ 3$ At distributions for $O B C$ events in $B^{0}{ }^{\circ} \ldots \ldots \ldots \ldots \ldots$

5.4 st distributions for $O B C$ events in $B^{+} B^{-} \ldots \ldots \ldots \ldots \ldots$

$5.5 \Delta t$ distributions for $\$ B C$ events in $B^{i 0} B^{\prime \prime} \ldots \ldots \ldots \ldots$

5.6 $\Delta t$ distributions for \$BC events in $B^{*} B^{*} \ldots \ldots \ldots \ldots \ldots$

5.7 At distributions for $1 d 1 \mathrm{r}$ events in $B^{0} \bar{B}^{*} \ldots \ldots \ldots \ldots \ldots$

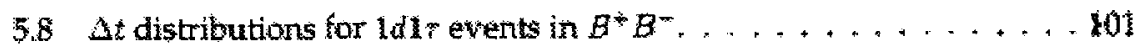

59 At distributions for $J / \%$-like events in $B^{0} b^{a} \ldots \ldots \ldots \ldots \ldots$

5.10 distributions for $J / t$ like exents in $B^{+} B^{*} \ldots \ldots \ldots$

5.11 a distributions for $X t r a$ events in $B^{n} \tilde{B}^{0}$. . . . . . . . . 108

5.12 at distribetions for $X$ trq events in $B^{+} B^{-} \ldots \ldots \ldots$

$5.13 \Delta t$ distributions for of -resonance events. . . . . . . . . . 111

6.1 It distributions and PDFs from fitting to separate lepton pairs of BB̈events. . . . . . . . . . . . . . . 117

6.2 Asymmetry plots fom fitting to separate lepton pairs of $B \tilde{B}$ events. . 118 
Lu At distributions and PDFs from simultaneous fitting to four lepton pairs of $B$ Bevents. . . . . . . . . . . . . . 119

6.4 Asymmetry plots from simultancots fitting to four lepton pairs of $B$ bevents. . . . . . . . . . . . . . . 120

$6.5 \Delta \pi_{\mathrm{s}}$ from individual and simultaneous fits in $B \bar{B}$ Monte Carlo . . 121

6.6 At distributions $m$ PDFs from fitting to geparate lepton pairs of on-resonance events. . . . . . . . . . . . . . . . 124

6.7 Asymmetry plots from fitting to separate lepton pairs of on-resonance

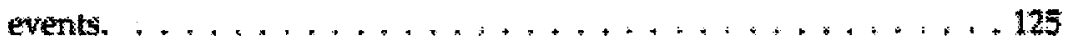

6.8 $\Delta t$ distributions and PDFs from fitting to separate lepton pairs of off-resonance events. $\ldots \ldots \ldots \ldots \ldots \ldots$

6.9 At distributions and PDFs from simultaneous fit to lepton pairs of

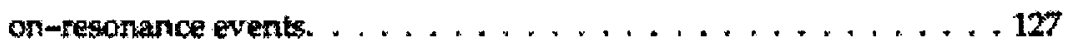

6.10 Asymmetry plats from simultaneous ftt bo lepton pairs of on-resonance events. $\ldots \ldots \ldots \ldots \ldots \ldots \ldots \ldots \ldots \ldots \ldots \ldots$

O11 At distributions and PDFs from simutlaneous $A_{1} \sim$ lepton pairs of off-resonance events. $\ldots \ldots \ldots \ldots \ldots \ldots \ldots \ldots \ldots$

6.12 Parameterizations of sigat $\infty \mathrm{C} 1 \mathcal{Q}_{\text {T resolution models. . . . } 131}$

$6.13 \Delta m_{1}$ from final fik with different angle $\sim$ ts in $B \bar{B}$ Monte Carto $\ldots 132$

$6.14 \Delta m_{q}$ from tinal fit with differen angle cuts in $B \tilde{B}$ Monte Carlo and data with right errorg $\ldots \ldots \ldots \ldots \ldots \ldots$

6.15 Corrected $\Delta m_{d}$ from data fit with different angle cuts $\ldots \ldots \ldots 135$

6.16 Toy te Carlo study results for the final fit $\ldots \ldots \ldots \ldots \ldots$

6.17 Likelihood distribution froco toy Morte Carlo study and talue from

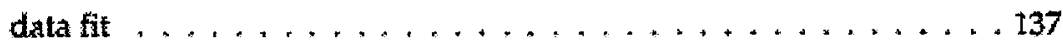

7.1 Systematics due to parameterizations for $\mathrm{OBC}, \mathrm{SBC}, 1 \mathrm{d1} 1 \mathrm{\text {and }} X \mathrm{Xta}, 143$ 
8.1 Comparison of $\Delta m_{\text {d }}$ from this analysis with other measurements and world average value $\ldots \ldots \ldots \ldots \ldots \ldots$ 


\section{List of Tables}

3.1 PEP-II beam parameters $\ldots \ldots \ldots \ldots \ldots \ldots \ldots \ldots$

3.20 sections, production and trigger rates. . . . . . . . 45

4.1 Dataset used for this analyis. $\ldots \ldots \ldots \ldots \ldots \ldots \ldots$

4.2 Sources of the leptons from bquark decay . . . . . . . . . 51

4.3 Electron identification requirements for Lopse and peryfight selections 53

4.4 Muon identification requirements for Laose and veryTight selections . 54 .

4.5 Summary of selection cuts employed on the ntuple level $\ldots \ldots, 62$

4.6. A complete overview of event types in the $B B$ statistics . . . . . . 69

4.7 statistics and efficiencies for $B^{0} B^{\circ}$ Monte Carlo for $e E$ after the selection cuts $\ldots \ldots \ldots \ldots \ldots \ldots \ldots \ldots \ldots$

4.8 statistics and efficiencies for $B^{0} g^{D}$ Monte Carlo for epafter the selection $n$ ts $\quad \ldots \ldots \ldots \ldots \ldots \ldots \ldots \ldots \ldots \ldots \ldots$

49 statistics and efficiencies for $B^{0} \bar{B}^{i}$ Monte Carlo for $\mu \mathrm{e}$ after the selec* tion cuts $\ldots \ldots \ldots \ldots \ldots \ldots \ldots \ldots$

4.10 statistics and efficiencies for $20 b^{3}$ Monte Carlo for $\mu$ ather the sem lection $N$ ts $\ldots \ldots \ldots \ldots \ldots \ldots, \ldots \ldots, \ldots \ldots$

4.11 statiskics and efficiencies for $B^{+} B^{-}$Monte Carlo for $\varepsilon E$ after the se-

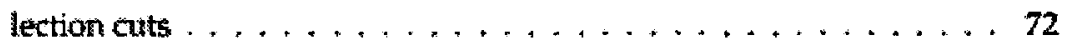

4.12 statistics and efficiencies for $B^{+} B^{-}$Monte Carto for $\mu$ after the lection $N$ ts 
anall

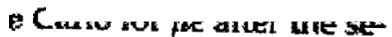

lectio- its

4.14 statisl $\quad$ lefficiencies for $B^{+} B^{-M}$ Mo Carlo for jps atter the se-

lection cuts

4.15 statistic and efficiencies for on-reson ce and off-resonance data

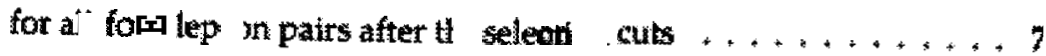

5.1 Rela1 Is of backgroutum uns ap mits from BB Monte Carlo

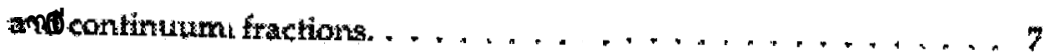

5.2 Values of diluticons for signal events. $\ldots \ldots \ldots \ldots$

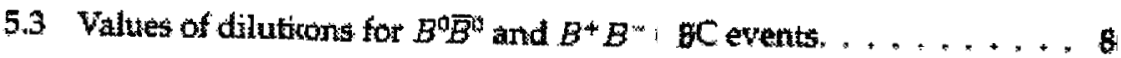

5.4 Values of fractions for $B^{*} B^{\circ}$ and $B^{+} B^{-}$AC events. . . . . . . 8

5.5 Values of resolution param _os for $B^{-B}$ and $B^{*} B^{-}$OBC events. .

5.6 Values of difutions for $B^{0} B^{4}$ and $B^{*} B^{-} ! 3 C$ erts. . . . . . . . . 9:

5.7 Values of fractouns fot $B^{\circ} \bar{B}^{0}$ and $B^{+} B$ SBC events. .........

5.8 Vafues of resolution parameters fo $B^{5} B^{2} \quad m 4 D^{+} D^{-1} S B C$ events. . . 94

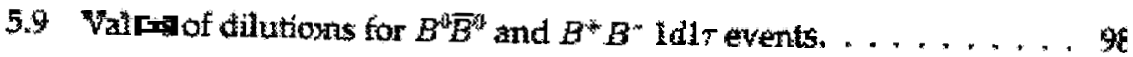

5.10 Values of tip fractiots for $B^{0} B^{0}$ and $B^{+} B^{-}$ldit events. . . . . . . . 96

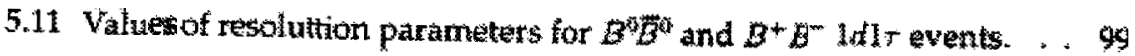

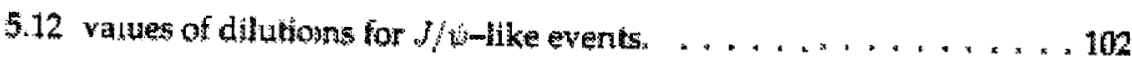

5.13 Values of dilutions for Extra events. $\ldots \ldots \ldots 106$

5.14 Values of resolution parameters for Extra events. . . . . . . . . 107

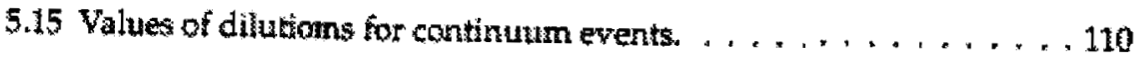

6.1 Fit results of individual lepton pairs using $B g$ Monte Carlo. . . . 155

6.2 Fit result of individual lepton pairs using on-regonance and offresonance data. $\ldots \ldots \ldots \ldots \ldots 122$ 
6.3 Simultaneous 0 results of 4 lepton pairs to $B \bar{B}$ Monte Carlo and on-resonance dac. . . . . . . . . . . . . . 123

6.4 Comparison of $\Delta n_{d}$ values from fits to full $B \tilde{B}$ MC and the toy MC. 131

6.5 Comparisons of $\Delta m_{d}$ and $\delta \Delta m_{d}$ between $B \bar{B}$ Monte Carlo and col data with differen 1 Tobs. . . . . . . . . . . . . . . . . 133

6.6 Reduction efficiencies for $B \bar{B}$ Monte Carlo and on-resonance data with different angle cuts $\ldots \ldots \ldots \ldots \ldots \ldots \ldots \ldots$

7.1 Summary of the systematic uncertainties $\ldots \ldots \ldots \ldots \ldots, 139$

7.2 Systematic error due to OBC resolution models. $\ldots \ldots \ldots \ldots, 144$ 


\section{ACKNOWLEDGMENTS}

I would like to express the deepest appreciation to my thesis advisor, Professor Andrew Lanktord, who accepted me as his Ph.D. student and provided me with the opportunity to carry out my research in the BABAR Collaboration. Without his patience, discrete gradance and persistent support this dissertation would not have been possible.

1 an very grateful to my committee members, Professor Myron Bander and Professor David Kitkby. David introdisced the to the $B$ mixing field and has been very supportive in conveying physical knowledge, as well as providing analysis tools. Myton served in both any candidacy and defense committees. 1 also benefited greatly from the courses I took with him.

The HEP group at UCl, particularly, Professor Jonas Schultz, Professor Mark Mandelkern, Professor Bill Molzon, and Professor Dennis Silverman, deserves many thanks for many useful discussions and encoutragements.

I would also like to thank Dr. Dieter Best, who first showed the the BABAR softwane and taught me how to work on the data analysis, for his great help, guidance and siguificant contributions to this analysis; Dr. Maarten Bruinsma for his insightful views and kind encouragement; Dr. Dave Stoker for many helpful discussions. This work would rot have been completed without the efforts of all the PEP-II and BABAR members. I think that it is appropriate to thank them all.

Without the anderstanding and support from my family I would th thave reached this stage. I want to thank my parents for their love and hopes of my success, which are the momentum helping me proceed even in very difficult situations. I also want to thank my wife Sulan for her selfess support and encouragement dur* ing my graduate study, and our son Kevin for the joy he brings to us. Thanks also go to the Iohnson family in Santa Ana for he!ping make our stay in Southern Calitomia very pleasat. 


\author{
ABSTRACT OF THE DISSERTATION \\ Measurement of the $B^{\prime} \bar{B}^{0}$ Oscillation Frequency Using Dilepton Events at BABAR \\ By \\ Ming Chao \\ Doctor of Philosophy in Physics \\ University of Califomia, Irvine, 2005 \\ Professor Andrew Lankford, Chair
}

This dissertation describes the measutement of the $b^{0} b^{\circ}$ oscillation frequency $\Delta m_{0}$ with a sample of $122 \times 10^{\delta} B \vec{B}$ pairs collected with the RABAR detector at the PEP-II asymmetric B Factory at the Stantord Linear Accelerator Center. A fully inclusive approach is used to select dilepton events in which $B$ meson decays sextileptonically and the lepton's charge is employed to identify the havor of each a meson. The oscillation frequency $\Delta m_{1}$ is extracted from the the time evolution of the dilepton everts. A maximum liketihood fit to the same sign and opposite sign events simultaneously gives:

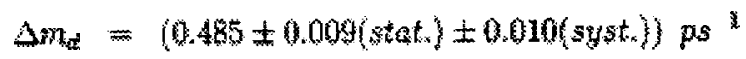

where the first uncertainfy is statistical and the second is systematic. This is one of the single most precise measurements of the $B^{0} \mathrm{~B}^{\mathrm{a}}$ ascillation frequency to date. 